\title{
Impact of kidney function on the occurrence of new-onset atrial fibrillation in patients with ST-elevation myocardial infarction
}

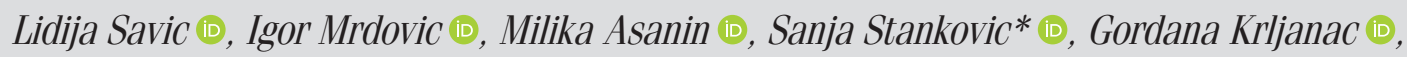 \\ Ratko Lasica (D, Mihajlo Viduljevic (iD \\ Coronary Care Unit and Cardiology Clinic, and *Center for Medical Biochemistry, \\ University Clinical Center of Serbia, Emergency Hospital; Belgrade-Serbia
}

\section{ABSTRACT}

Objective: In this study, we aimed to examine the prognostic impact of decreased kidney function at admission on the occurrence of new-onset atrial fibrillation (AF) in patients with ST-elevation myocardial infarction (STEMI) treated with primary percutaneous coronary intervention (pPCI).

Methods: The study enrolled 3,115 consecutive patients with STEMI. Kidney function was assessed by estimation of the glomerular filtration rate (eGFR) at admission. Patients with cardiogenic shock at admission, patients on hemodialysis, and patients with a medical history of previous AF (paroxysmal, persistent, or permanent) were excluded. The follow-up period was six years.

Results: New-onset AF occurred in $215(6.9 \%)$ patients, $75(34.9 \%)$ patients presented with AF, and $140(65.1 \%)$ patients developed AF after pPCI. The median time of AF occurrence in patients who did not present with AF was 4.5 (interquartile range 1-25) hours after pPCl. New-onset AF was associated with a higher short- and long-term mortality. In the multiple logistic regression analysis, all stages of reduced kidney function were independent predictors for the occurrence of new-onset $A F$, and negative prognostic impact increased with the deterioration of kidney function: eGFR $<90 \mathrm{~mL} / \mathrm{min} / \mathrm{m}^{2}$, hazard ratio (HR) 1.96, 95\% confidence interval (CI) 1.42-2.89, p=0.011; eGFR 60-89 mL/min/m², HR 1.54, 95\% Cl 1.13-2.57, p=0.045; eGFR 45-59 mL/min/m²-, HR 2.09, 95\% Cl 1.24-2.85, p=0.023; eGFR 30-44 mL/min/m²-, HR 2.93, 95\% Cl 1.64-5.29, p<0.001; eGFR $15-29 \mathrm{~mL} / \mathrm{min} / \mathrm{m}^{2}-$, HR 5.51, $95 \% \mathrm{CI} 2.67-11.39, \mathrm{p}<0.001$.

Conclusion: Decreased kidney function was significantly associated with the occurrence of new-onset AF, and its impact increased with the deterioration in kidney function, starting with an eGFR value of $90 \mathrm{~mL} / \mathrm{min} / \mathrm{m}^{2}$. New-onset AF was an independent predictor of long-term allcause mortality in the analyzed patients.

Keywords: new-onset atrial fibrillation, kidney function, myocardial infarction

Cite this article as: Savic L, Mrdovic I, Asanin M, Stankovic S, Krljanac G, Lasica R, et al. Impact of kidney function on the occurrence of new-onset atrial fibrillation in patients with ST-elevation myocardial infarction. Anatol J Cardiol 2021; 25: 638-45.

\section{Introduction}

Atrial fibrillation (AF) frequently complicates acute ST-elevation myocardial infarction (STEMI) (1-3). New-onset AF complicating STEMI is defined as AF occurring during the index event. The incidence of new-onset AF in patients with STEMI is reduced by the introduction of primary percutaneous coronary intervention (pPCl) in comparison with the thrombolytic era, and it ranges from $4.8 \%$ to $7.7 \%(1,4,5)$. Multiple studies have shown that any type of AF that complicates STEMI is an independent predictor of mortality and adverse cardiovascular events in short-term and long-term follow-ups (1, 2, 5-10). However, there is a study showing that only before $A F$, but not new-onset $A F$, is an independent predictor of adverse events in patients with STEMI (11). Many factors and mechanisms may be related to new-onset AF development in patients with STEMI $(2,10)$. Some of these factors are excess catecholamine release or hemodynamic impairment, which is related to acute ischemia $(2,4,10)$. Apart from factors directly linked to ischemia, chronic states, that is comorbidities can also influence frequent occurrence of new-onset AF in patients with STEMI, most probably through the mechanism of structural atrial remodeling present in these

Address for Correspondence: Lidija Savic, MD, Coronary Care Unit and Cardiology Clinic,

University Clinical Center of Serbia, Emergency Hospital; Belgrade-Serbia

Phone: +381 113662331 E-mail: lidijasavic2007@gmail.com

Accepted Date: 24.03.2021 Available Online Date: 04.08.2021

(C) Copyright 2021 by Turkish Society of Cardiology - Available online at www.anatoljcardiol.com DOI:10.5152/AnatolJCardiol.2021.35332 


\section{HIGHLIGHTS}

- Kidney function was an independent predictor for the occurrence of new-onset atrial fibrillation (AF).

- The independent predictive impact increased with the decline kidney function, starting with an estimation of the glomerular filtation rate (eGFR) value of $90 \mathrm{~mL} / \mathrm{min} /$ $\mathrm{m}^{2}$.

- New-onset AF was an independent predictor of longterm all-cause mortality in the analyzed patients.

patients prior to the occurrence of acute ischemia (2). It is well known that chronic kidney disease (CKD), as a global health problem, is significantly associated with a poor prognosis in patients with STEMI $(1,12)$. Patients with CKD are more likely to develop $A F$ than the general population, and the risk of $A F$ occurrence increases with declining kidney function (1, 13-17). There are studies which show that CKD is also an independent predictor of the occurrence of new-onset $A F$ in patients with myocardial infarction (both STEMI and non-STEMI), (1-12). But there are little data analyzing the prognostic impact of declining kidney function on the occurrence of new-onset $\mathrm{AF}$ in patients with STEMI treated with $\mathrm{pPCI}$.

In this study we aimed to examine the prognostic impact of declining kidney function on the occurrence of new-onset $A F$ in patients with STEMI who had been treated with $\mathrm{pPCl}$ and to analyze the prognostic impact of new-onset AF on long-term all-cause mortality in these patients.

\section{Methods}

\section{Study population, data collection, and definitions}

This study enrolled 3,115 consecutive patients, hospitalized between February 2006 and December 2012, who were included in the prospective Clinical Center of Serbia STEMI Register. The goal of the prospective Clinical Center of Serbia STEMI Register has been published elsewhere (18). In brief, the objective of the register is to gather complete and representative data on the management and short- and long-term outcomes of patients with STEMI, undergoing primary $\mathrm{PCl}$ in the center. The study protocol was approved by the Local Research Ethics Committee. All the consecutive patients with STEMI aged 18 or older, who were admitted to the coronary care unit after undergoing $\mathrm{pPCl}$ in the center, were included in the register. Patients with cardiogenic shock at admission, those on hemodialysis, and patients with a medical history of previous AF (paroxysmal, persistent, or permanent) were excluded from this study. Patients with no medical history of previous AF who presented with AF were included.

Coronary angiography was performed via the femoral approach. Primary $\mathrm{PCl}$ and stenting of the infarct-related artery (IRA) was performed according to the standard technique. Aspirin $300 \mathrm{mg}$, and clopidogrel $600 \mathrm{mg}$, were administered to all the eligible patients before pPCl. Selected patients, with visible intracoronary thrombi, were also given the GP IIb/IIla receptor inhibitors during $\mathrm{pPCl}$. Flow grades were assessed according to the thrombolysis in myocardial infarction (TIMI) criteria. Following $\mathrm{pPCl}$, the patients were treated according to current guidelines.

Demographic, baseline clinical, angiographic, and procedural data were collected and analyzed. Hypertension, diabetes mellitus and hyperlipidemia were recorded according to the patients' clinical information, use of medication for these conditions, and laboratory results. Kidney function was assessed by estimation of the glomerular filtration rate (eGFR) at admission using the modification of diet in renal disease (MDRD) equation. A value of $<90 \mathrm{~mL} / \mathrm{min} / \mathrm{m}^{2}$ was considered to be reduced baseline eGFR; and, in relation to the eGFR value, reduced kidney function was classified into the following stages- mildly reduced (eGFR $60-89 \mathrm{~mL} / \mathrm{min} / \mathrm{m}^{2}$ ), mildly to moderately reduced (eGFR $45-59 \mathrm{~mL} / \mathrm{min} / \mathrm{m}^{2}$ ), moderately to severely reduced (eGFR $30-44$ $\mathrm{mL} / \mathrm{min} / \mathrm{m}^{2}$ ), and severely reduced (eGFR $15-29 \mathrm{~mL} / \mathrm{min} / \mathrm{m}^{2}$ ) (19).

Echocardiographic examination was performed within the first three days of $\mathrm{pPCl}$. Left ventricular ejection fraction (LVEF) was assessed according to the biplane Simpson method, in classical two- and four-chamber apical projections. LVEF was missing in $10 \%$ of patients. The missing data were imputed via the single imputation method.

New-onset AF was defined as electrocardiographic or monitoring evidence of a sustained (lasting at least 30 seconds) irregularly irregular rhythm ( $R-R$ intervals) with the absence of $P$ waves in patients with no medical history of previous AF.

Patients were followed- up for six years after enrollment. Follow-up data were obtained by scheduled telephone interviews and during outpatient visits. We analyzed six-year allcause mortality.

\section{Statistical analysis}

Categorical variables were expressed as frequency and percentage, and continuous variables were expressed as median value (med) with $25^{\text {th }}$ and $75^{\text {th }}$ quartiles (IOR). Analysis for normality of data was performed using the Kolmogorov-Smirnov test. Baseline differences between groups were analyzed using the Mann-Whitney $U$ test for continuous variables and the Pearson $X^{2}$ test for categorical variables. Multiple logistic regression was used to define independent predictors of newonset AF (backward method, with $p<0.10$ for entrance into the model). The receiver operating characteristic (ROC) curve was used to test the predictive power of kidney function on newonset AF development. The Kaplan-Meier method was used for constructing the probability curves for a six-year survival, and the difference between patients with and without new-onset AF was tested with the log-rank test. Multiple Cox analysis (backward method, with $p<0.10$ for entrance into the model) was used to identify independent risk factors for the occurrence of sixyear all-cause mortality. A $p$ value $<0.05$ was considered significant. The Statistical Package for the Social Sciences statistical software, version 19, was used for data analysis (SPSS Inc, Chicago, IL, US). 


\begin{tabular}{|c|c|c|c|}
\hline Characteristics & Atrial fibrillation $n=215$ & No atrial fibrillation $n=2,900$ & $P$-value \\
\hline Age, years med (IQR) & $67(57.5-75)$ & $59(51-68)$ & $<0.01$ \\
\hline Female, n (\%) & 73 (33.95) & 804 (27.78) & 0.125 \\
\hline Body mass index, med ( IOR) & $26.51(24.7-29.81)$ & $26.12(24.82-28.45)$ & 0.747 \\
\hline Previous MI, n (\%) & $29(13.48)$ & $298(10.27)$ & 0.138 \\
\hline Previous AP, n (\%) & $29(13.48)$ & $208(7.18)$ & 0.001 \\
\hline Previous PCI, n (\%) & $2(0.92)$ & $9(0.31)$ & 0.132 \\
\hline Previous stroke, n (\%) & $10(4.65)$ & $111(3.89)$ & 0.054 \\
\hline Diabetes, n (\%) & $44(20.45)$ & $556(19.17)$ & 0.758 \\
\hline Hypertension, n (\%) & $163(75.81)$ & $1,957(67.42)$ & 0.018 \\
\hline HLP, n (\%) & $97(45.11)$ & $1,793(61.82)$ & $<0.01$ \\
\hline Smoking, n (\%) & $78(36.27)$ & $1,580(54.48)$ & $<0.01$ \\
\hline COPD, n (\%) & $18(8.18)$ & $158(5.46)$ & 0.224 \\
\hline Pain duration, hours med (IQR) & $2(1-4)$ & $3(1.5-4)$ & 0.835 \\
\hline HF at admission, $\mathrm{n}(\%)$ & $71(33.03)$ & $320(11.03)$ & $<0.01$ \\
\hline Systolic BP (mm Hg) at admission, med (IQR) & $130(120-140)$ & $140(120-150)$ & $<0.01$ \\
\hline HR at admission, med (IOR) & $88(74-103)$ & $80(70-90)$ & $<0.01$ \\
\hline Anterior infarction, n (\%) & $91(42.32)$ & $1,167(40.24)$ & 0.803 \\
\hline 3-vessel disease, n (\%) & $80(37.21)$ & $757(26.1)$ & $<0.01$ \\
\hline Preprocedural flow TIMI 0, n (\%) & $174(80.93)$ & $1975(68.1)$ & 0.003 \\
\hline LM stenosis, n (\%) & $16(6.37)$ & $173(5.96)$ & 0.158 \\
\hline Stent implantation, $\mathrm{n}(\%)$ & $181(84.12)$ & $2,733(94.24)$ & $<0.01$ \\
\hline Postprocedural flow TIMI <3, n (\%) & $30(13.93)$ & $116(4.2)$ & $<0.01$ \\
\hline Acute stent thrombosis, $\mathrm{n}(\%)$ & $5(2.32)$ & $32(1.12)$ & 0.065 \\
\hline LVEF (\%), med (IOR) & $42(37-50)$ & $50(40-55)$ & $<0.01$ \\
\hline Left atrial AP diameter, med (IQR) & $3.91(3.61-4.41)$ & $3.80(3.51-4.40)$ & 0.669 \\
\hline Mitral valve disease ${ }^{*}, \mathrm{n}(\%)$ & $10(4.76)$ & $87(3.03)$ & 0.127 \\
\hline CK, med (IOR) & $1,825(995-337)$ & $1,869(998-3,391)$ & 0.280 \\
\hline Troponin I ( $\mu \mathrm{g} / \mathrm{L})$ med (IQR) & $30(11-96)$ & $30.9(10.6-96.5)$ & 0.674 \\
\hline Hemoglobin g/L, med (IQR) & $138(125-150)$ & $142(131-152)$ & $<0.01$ \\
\hline Glucose at admission, med (IOR) & $8.21(6.62-11.12)$ & $7(5.92-9.12)$ & $<0.01$ \\
\hline Creatinine at admission $\mu \mathrm{mol} / \mathrm{L}$, med (IOR) & $106(98-115)$ & $89(88-91)$ & $<0.01$ \\
\hline eGFR mL/min/m² med (IQR) & $82.92(61.78-103.72)$ & $92.83(71.78-115.87)$ & $<0.01$ \\
\hline $\mathrm{eGFR} \geq 90 \mathrm{~mL} / \mathrm{min} / \mathrm{m}^{2}, \mathrm{n}(\%)$ & $30(13.9)$ & $1,329(45.87)$ & $<0.01$ \\
\hline eGFR 60-89 mL/min/m², n (\%) & $108(50.38)$ & $1147(39.56)$ & $<0.01$ \\
\hline eGFR $45-69 \mathrm{~mL} / \mathrm{min} / \mathrm{m}^{2}, \mathrm{n}(\%)$ & $38(17.72)$ & $280(9.67)$ & $<0001$ \\
\hline eGFR 30-44 mL/min/m², n (\%) & $24(11.36)$ & $109(3.75)$ & $<0.01$ \\
\hline eGFR 15--29 mL/min/m², n (\%) & $15(6.41)$ & $35(0.93)$ & $<0.01$ \\
\hline
\end{tabular}

\section{Results}

New-onset AF occurred in $215(6.9 \%)$ patients. Among the patients with $A F, 75(34.9 \%)$ presented with $A F$, and $140(65.1 \%)$ developed $\mathrm{AF}$ after $\mathrm{pPCl}$. The median time of AF occurrence in patients who did not present with AF was 4.5 (IOR 1-25) hours after pPCI. Median duration of new-onset AF was 18 (IQR 6.5-30) hours. Baseline demographic, clinical and laboratory data, angi- ographic characteristics, baseline kidney function, as well as ejection fraction (EF) in patients, who did and did not develop new-onset AF are shown in Table 1. In comparison with patients who did not have new-onset AF, patients with new-onset AF were older. The following were more frequently present in these patients- previous coronary disease, hypertension, cardiac insufficiency, lower systolic blood pressure and higher cardiac frequency at admission, three-vessel coronary disease, occlu- 


\begin{tabular}{|c|c|c|c|}
\hline In hospital & $\begin{array}{c}\text { New-onset AF } \\
\quad \mathrm{n}=215\end{array}$ & $\begin{array}{c}\text { No AF } \\
n=2,900\end{array}$ & $P$-value \\
\hline Aspirin, n (\%) & $215(100)$ & 2,899 (99.99) & 0.785 \\
\hline Clopidogrel, n (\%) & 214 (99.99) & $2,800(96.55)$ & 0.872 \\
\hline Heparin, n (\%) & $215(100)$ & $2,410(83.11)$ & 0.009 \\
\hline Beta blockers, n (\%) & $160(74.41)$ & $2,534(87.37)$ & 0.504 \\
\hline ACE inhibitors, $n(\%)$ & 137 (63.72) & 2,168 (74.75) & 0.001 \\
\hline Statin, n (\%) & $173(80.46)$ & $2,138(73.72)$ & 0.145 \\
\hline Diuretics, n (\%) & $97(45.12)$ & 399 (13.75) & $<0.001$ \\
\hline Digitalis, n (\%) & $59(27.45)$ & $49(1.68)$ & $<0.001$ \\
\hline Amiodarone, $\mathrm{n}(\%)$ & $59(27.45)$ & $26(0.89)$ & $<0.001$ \\
\hline Inotropes & $54(25.12)$ & $138(4.76)$ & $<0.001$ \\
\hline At discharge & $n=173^{*}$ & $\mathrm{n}=2,809^{*}$ & \\
\hline Aspirin, n (\%) & 171 (98.89) & 2,539 (90.38) & 0.555 \\
\hline Clopidogrel, n (\%) & 171 (98.89) & $2,521(90.25)$ & 0.952 \\
\hline Beta blockers, n (\%) & $170(98.26)$ & 2,438 (86.79) & 0.224 \\
\hline ACE inhibitors, $n(\%)$ & $133(76.87)$ & $2,271(80.84)$ & 0.764 \\
\hline Statins, n (\%) & 143 (82.65) & 2,539 (90.38) & 0.985 \\
\hline Amiodarone, $\mathrm{n}(\%)$ & $72(41.62)$ & $95(3.38)$ & $<0.001$ \\
\hline Digitalis, $\mathrm{n}(\%)$ & $5(2.89)$ & $10(0.36)$ & $<0.001$ \\
\hline Diuretic, $n(\%)$ & $49(28.32)$ & 429 (15.27) & $<0.001$ \\
\hline Oral anticoagulant therapy**, $\mathrm{n}(\%)$ & 130 (75.12) & $5(0.17)$ & $<0.001$ \\
\hline
\end{tabular}

\begin{tabular}{|c|c|c|c|}
\hline Variable & OR & CI & $P$-value \\
\hline $66-75$ years & 1.80 & $1.20-2.69$ & 0.040 \\
\hline$>75$ years & 2.40 & $1.47-3.19$ & $<0.001$ \\
\hline Heart failure at admission & 2.64 & $1.92-3.93$ & $<0.001$ \\
\hline Postprocedural TIMI <3 & 2.13 & $1.33-3.42$ & $<0.001$ \\
\hline IRA occluded (TIMI=0) & 1.67 & $1.18-2.36$ & 0.027 \\
\hline $\mathrm{eGFR}<90 \mathrm{~mL} / \mathrm{min} / \mathrm{m}^{2}$ & 1.96 & $1.42-2.89$ & 0.011 \\
\hline eGFR $60-89 \mathrm{~mL} / \mathrm{min} / \mathrm{m}^{2}$ & 1.54 & $1.13-2.57$ & 0.045 \\
\hline eGFR $45-59 \mathrm{~mL} / \mathrm{min} / \mathrm{m}^{2}$ & 2.09 & $1.24-2.85$ & 0.023 \\
\hline eGFR 30-44 mL/min/m² & 2.93 & $1.64-5.29$ & $<0.001$ \\
\hline eGFR $15-29 \mathrm{~mL} / \mathrm{min} / \mathrm{m}^{2}$ & 5.51 & $2.67-11.39$ & $<0.001$ \\
\hline
\end{tabular}

sion of the infarct-related artery (pre-procedural flow $\mathrm{TIMI}=0$ ) at the initial angiogram, postprocedural flow $\mathrm{TIMI}<3$, and a lower value of EF. Patients with new-onset AF had a lower average value of eGFR on admission than patients without AF.

Data on therapy during hospitalization and at discharge is presented in Table 2. All the analyzed patients with new-onset AF were converted into sinus rhythm with medication (amioda- rone), or they converted spontaneously on myocardial revascularization. The use of beta blockers, amiodarone, and digitalis was in accordance with the current guidelines and the existing practice in our coronary unit. No patients with AF were treated with direct current cardioversion.

Independent predictors for the occurrence of new-onset AF are presented in Table 3. 


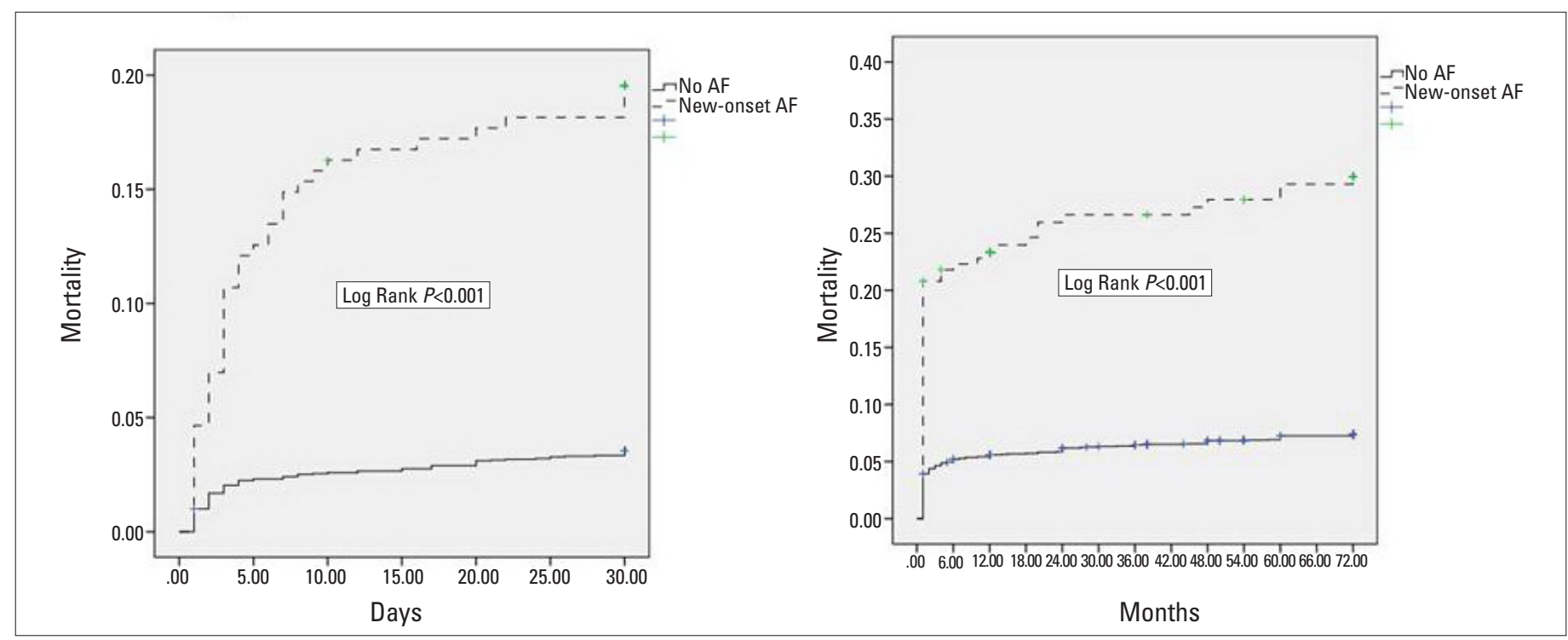

Figure 1. Kaplan-Meier curves showing mortality during six-year follow-up according to the development of new-onset atrial fibrillation

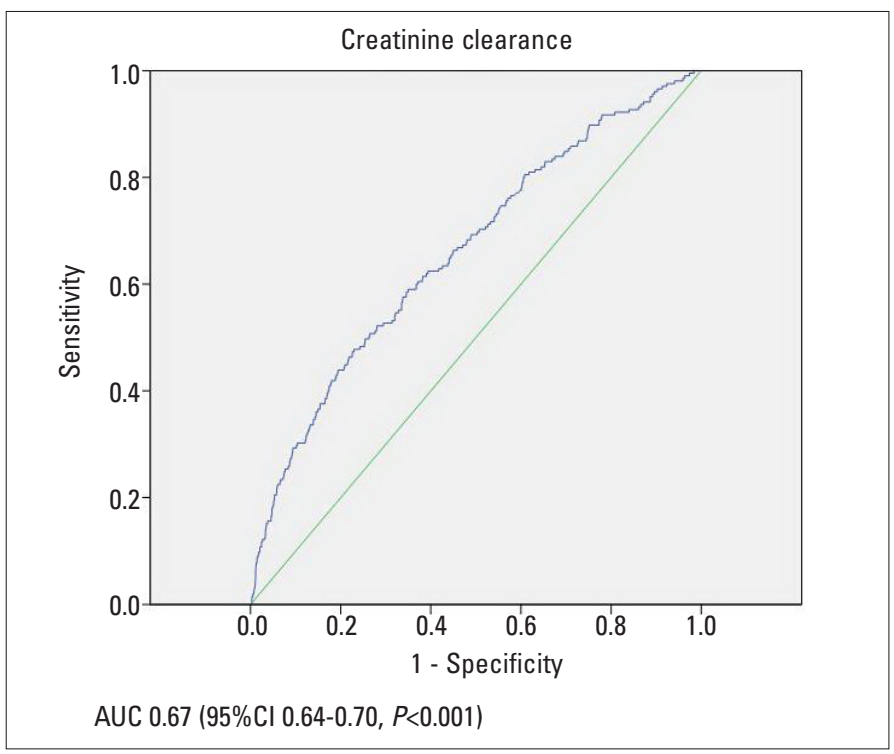

Figure 2. Receiver operating characteristic curve for estimated glomerular filtration rate

In the multiple logistic regression analysis, all stages of reduced kidney function were significantly associated with the occurrence of new-onset AF. The risk of occurrence of newonset $A F$ increased with the worsening kidney function.

Figure 1 presents the discriminative ability of kidney function (eGFR) to predict the occurrence of new-onset AF (ROC curve). In-hospital, 30-day, one-year, and six-year mortalities were significantly higher in patients with new-onset AF compared with that in patients with no AF: in-hospital mortality of $19.62 \%$ vs. $3.12 \%$, respectively, $p<0.001 ; 30$-day mortality of $20 \%$ vs. $3.58 \%$, respectively, $p<0.001$; one-year mortality of $23.26 \%$ vs. $5.58 \%, p<0.001$; and six-year mortality of $46.57 \%$ vs. $6.93 \%$, respectively, $p<0.001$.

Kaplan-Meier curves estimating the probability of mortality during follow-up in patients with new-onset AF and with no AF are shown in Figure 2.
After adjustment for potential confounders, including age, heart failure at admission, EF, postprocedural TIMI flow $<3$, and kidney function; new-onset $\mathrm{AF}$ remained an independent predictor of mortality throughout the follow-up period-hazard ration 1.85 , (95\% confidence interval $1.25-2.45), p=0.024$.

\section{Discussion}

The results of this study show that declining kidney function at admission was more frequently present in patients with newonset AF compared with that in patients with no AF. Decreased kidney function at admission was significantly associated with the occurrence of new-onset AF. The impact increased with the decline in kidney function, starting with an eGFR value of $90 \mathrm{~mL} /$ $\mathrm{min} / \mathrm{m}^{2}$. New-onset AF was an independent predictor of longterm all-cause mortality in the analyzed patients.

The incidence of new-onset AF in the patients from this study is consistent with data that can be found in literature related to patients treated with $\mathrm{pPCI}(1,2,5,7,20)$. The clinical characteristics of the patients with AF from this study mostly correlate with the results found in literature; the common finding is that patients with new-onset AF are older; more commonly have previous coronary disease as well as a greater number of chronic comorbidities and cardiac insufficiency and a poor coronographic finding are more commonly present at admission. Patients with new-onset AF generally have a lower EF after infarction (1, 2, 5, 8-10). However, although diabetes mellitus and hypertension are considered to be predictors of $\mathrm{AF}$ occurrence in our study, there was no significant difference in the prevalence of diabetes in patients with or without new-onset $A F_{\text {, }}$ which has also been noted in literature, regarding the population of patients with STEMI $(1,8,13)$. At hospital discharge, the application of dual antithrombotic therapy and other therapy with beneficial influence on the prognosis of patients with STEMI (e.g., beta blockers and ACE inhibitors) did not significantly differ 
between the analyzed patients with new-onset $A F$ and patients without new-onset AF.

The highest number of independent predictors for the occurrence of new-onset $\mathrm{AF}$ in patients with acute myocardial infarction, both in this study and in other studies, have been connected to ischemia (cardiac insufficiency at admission, IRA occlusion, postprocedural TIMI flow $<3$ ) and almost always, a smaller number of independent predictors are chronic conditions (comorbidities) $(1,2,5,20)$. In this study, reduced baseline kidney function was the only comorbidity which was independently associated with the occurrence of new-onset AF. In a study by Cosentino et al. (1) it was found that CKD (the only chronic comorbidity) was an independent predictor for the occurrence of new-onset AF in patients with STEMI and NSTEMI. As opposed to our study, patients with STEMI and NSTEMI were analyzed, and the authors of the abovementioned study did not analyze the mildly decreased values of eGFR, the value of eGFR $<60 \mathrm{~mL} / \mathrm{min} / \mathrm{m}^{2}$ was considered as CKD. The authors also have shown that both CKD and new-onset AF were independent predictors of long-term mortality in the analyzed patients; whereas in patients with moderate and severe CKD, mortality was greater if new-onset AF was also present. A study by Şerban et al. (2) found that CKD at admission (also the only chronic comorbidity) was an independent predictor for the occurrence of new-onset AF and AF occurring at patient admission, that is as the authors named it - "ischemia related AF". CKD at admission was a stronger independent predictor for the occurrence of new-onset AF than other known predictors of $A F$, such as cardiac insufficiency and left atrial diameter. The discriminative ability of eGFR for the occurrence of new-onset AF in the study by Şerban et al. (2) was almost identical to the finding of this study. However, creatinine clearance of $<60 \mathrm{~mL} / \mathrm{min}$ was considered as decreased kidney function in the aforementioned paper unlike in this study, and the prognostic impact of the degree of CKD was not analyzed, and only in-hospital mortality was analyzed. This study demonstrated that the impact of new-onset AF on mortality persisted in the long-term - six-year follow- up, as well. The prognostic impact of the early stages of CKD, that is mildly decreased eGFR values, on the occurrence of AF was analyzed more in studies examining CKD patient registers (13). In a study by Soliman et al. (13), analyzing AF occurrence in a population of patients with preterminal CKD, it was found that AF prevalence was two to three times higher in patients with mild-to-moderate CKD than that in the general population. In this study, the prognostic impact of mildly and mildly to moderately decreased eGFR on the occurrence of new-onset AF was lower than in the aforementioned study; this study, however, analyzed patients with STEMI, and the occurrence of new-onset AF in STEMI is also significantly influenced by mechanisms related to ischemia itself. As in the study by Soliman et al. (13), the prevalence of AF in mild-to-moderate CKD was similar to the prevalence in patients with terminal CKD, and the authors believed that the mechanisms through which decreased kidney function impacted the occurrence of $\mathrm{AF}$ were active in the earliest stage of kidney function deterioration (16).
The explanation for the predictive impact of CKD on the more frequent occurrence of $\mathrm{AF}$ as an infarction complication can be found in the more frequent existence of comorbidities, which are risk factors not only for CKD but also for AF (e.g., hypertension, diabetes mellitus, etc.), and also in the higher sensitivity of patients with CKD to the newly occurring hemodynamic changes $(2,15,16)$. Patients with CKD are older, and age is also a risk factor for AF occurrence (17). However, in this study, declining kidney function was independently associated with the occurrence of new-onset $A F$ along with the age of the patient. In addition sympathetic over activity often occurs in abnormal kidney function (whether in acute kidney injury or in CKD) and is more pronounced with the decline in eGFR, thus facilitating the occurrence of $A F$ in acute ischemia $(1,2)$. It has been shown that chronic inflammation, a typical characteristic of CKD from its earliest stages, is also an independent predictor of the occurrence of $A F$ in infarction $(1,13)$.

Patients with new-onset AF have higher in-hospital mortality and a higher mortality in mid-term and long-term follow-up, which has been demonstrated by the results of numerous studies $(1-4,7,8,20)$. However, in a study by Topaz et al. (11), only previous AF was an independent predictor of long-term mortality in patients with STEMI, while the occurrence of new-onset AF was not, although there was a trend toward increased shortterm and long-term mortality. The authors explained this finding by a relatively small number of patients with new-onset $A F$ and a relatively small number of events during follow-up. In a large database of 106,708 patients with myocardial infarction, newonset AF was associated with a $20 \%$ higher adjusted in-hospital mortality risk. However patients with AF at hospital admission had a mortality rate that was no different from that of patients with sinus rhythm, presumably a reflection of prior (persistent) $\mathrm{AF}$ as opposed to de novo AF $(1,21)$. In this study, in-hospital mortality in patients with AF was greater than in some other studies, (1-11) but the mortality during follow-up was mainly in correlation with the findings from literature $(8,9)$. The differences in short-term mortality could be explained by the differences in the inclusion of patients with AF into the study; this study excluded patients who had no medical data confirming any type of AF before admission. Therefore, we attempted to isolate patients in whom AF was a complication of ischemia itself and avoiding possible "overrating" of the occurrence of this type of arrythmia in patients with STEMI.

Clinical significance of the study: As significant association of declining baseline kidney function with the occurrence of new-onset AF was registered even in patients with a mild decrease in eGFR, it is important to assess eGFR at hospital admission. This is necessary even in patients with normal values of serum creatinine (as patients with mildly decreased eGFR most often have normal values of serum creatinine) for identifying those among them who are at risk of developing new-onset AF, which will impact their prognosis. Further studies should analyze the potential benefit from therapy which has a positive impact on the prognosis of patients with STEMI, and it should 
also investigate possible prophylactic antiarrhythmic therapy in this particular group of patients (2).

\section{Study limitations}

This study was observational, but controlled, prospective, and included consecutive patients with no missing data, limiting possible selection bias. Although patients with a medical history of AF were excluded, it was not possible to completely exclude the possible existence of (short-lasting) asymptomatic episodes of $\mathrm{AF}$ before admission. Repeated occurrence of AF during follow-up was not analyzed. Kidney function at hospital admission can be a chronic condition or an acute decline of kidney function. As the average time from the onset of complaints to hospital admission was around three hours, and as the blood for determining creatinine levels was taken immediately upon admission (before $\mathrm{pPCl}$ ), we believe that STEMI related hemodynamic status could not have significantly influenced kidney function and that the values of eGFR in the patients included in this study were predominately an indicator of a chronic state, rather than of a temporary worsening. In addition, patients with cardiogenic shock at admission were excluded from the study. The eGFR value $<90 \mathrm{~mL} / \mathrm{min} / \mathrm{m}^{2}$ was considered to be a reduced baseline eGFR, but this may solely be a reflection of age-related physiological decline in some patients. Kidney function was assessed with the use of the MDRD equation, which also has its limitations $(22,23)$. The rates of urinary albumin and protein excretion were not measured, which are factors that may influence the independent impact of kidney function on the risk of $A F(17)$. In this study, patients were treated with clopidogrel; and none of them were treated with the more recently developed antiplatelet drugs (prasugrel and/or ticagrelor), and $\mathrm{pPCl}$ was predominantly performed using bare metal stents. Ticagrelor, prasugrel, and/or the new generation of drug-eluting stents or biodegradable polymers were not available for routine administration to patients at the time of their enrollment into the register, which may have influenced the prognosis of the analyzed patients. The study was not designed to evaluate whether changing pharmacological treatment would have an impact on the longterm outcome in the analyzed patients.

\section{Conclusion}

Reduced kidney function at admission was associated with the occurrence of new-onset AF in patients with STEMI treated with primary $\mathrm{PCl}$, and the impact started already with mildly decreased eGFR and increased with its further decline. Newonset AF was an independent predictor of short-term and longterm mortality in the analyzed patients. Determining the value of eGFR at admission can help in early identification of patients who are at risk of the occurrence of new-onset AF and who may benefit from closer in-hospital monitoring, more frequent checkups during follow-up, and more intensive secondary prevention.

Acknowledgments: The authors express their gratitude to the physicians and nurses of the coronary unit and catheterization laboratory who participated in the primary PCI program.
Conflict of interest: None declared.

Peer-review: Externally and internally peer-reviewed.

Author contributions: Concept-L.S., M.A.; Design-L.S.; Supervision - L.S., I.M.; Fundings - None; Materials - L.S.; Data collection \&/or processing - L.S., S.S., G.K.; Analysis \&/or interpretation - L.S., I.M., S.S., G.K.; Literature search - S.S., R.L., M.V.; Writing - L.S., R.L.; Critical review - L.S., I.M., M.A.

\section{References}

1. Cosentino N, Ballarotto M, Campodonico J, Milazzo V, Bonomi A, Genovesi $S$, et al. Impact of Glomerular Filtration Rate on the Incidence and Prognosis of New-Onset Atrial Fibrillation in Acute Myocardial Infarction. J Clin Med 2020; 9: 1396. [Crossref]

2. Şerban RC, Şuş I, Lakatos EK, Demjen Z, Ceamburu A, Fişcă PC, et al. Chronic kidney disease predicts atrial fibrillation in patients with ST-segment elevation myocardial infarction treated by primary percutaneous coronary intervention. Acta Cardiol. 2019; 74: 472-9. [Crossref]

3. Gorenek B, Kudaiberdieva G. Atrial fibrillation in acute ST-elevation myocardial infarction: clinical and prognostic features. Curr Cardiol Rev 2012; 8: 281-9. [Crossref]

4. Mrdovic I, Savic L, Krljanac G, Perunicic J, Asanin M, Lasica R, et al. Incidence, predictors, and 30-day outcomes of new-onset atrial fibrillation after primary percutaneous coronary intervention: insight into the RISK-PCI trial. Coron Artery Dis 2012; 23: 1-8. [Crossref]

5. Congo KH, Belo A, Carvalho J, Neves D, Guerreiro R, Pais JA, et al. New-Onset Atrial Fibrillation in St-Segment Elevation Myocardial Infarction: Predictors and Impact on Therapy And Mortality. Arq Bras Cardiol 2019; 113: 948-57. [Crossref]

6. Hindricks G, Potpara T, Dagres N, Arbelo E, Bax JJ, BlomströmLundqvist C, et al.; ESC Scientific Document Group. 2020 ESC Guidelines for the diagnosis and management of atrial fibrillation developed in collaboration with the European Association for Cardio-Thoracic Surgery (EACTS): The Task Force for the diagnosis and management of atrial fibrillation of the European Society of Cardiology (ESC) Developed with the special contribution of the European Heart Rhythm Association (EHRA) of the ESC. Eur Heart J 2021; 42: 373-498. [Crossref]

7. Schmitt J, Duray G, Gersh BJ, Hohnloser SH. Atrial fibrillation in acute myocardial infarction: a systematic review of the incidence, clinical features and prognostic implications. Eur Heart J 2009; 30: 1038-45. [Crossref]

8. Hwang KK, Eom SY, Lee SY, Kim SM, Cho MC, Kim YJ, et al.; other Korea Acute Myocardial Infarction Registry Investigators. Atrial Fibrillation on Admission Is Related With Higher Mortality in ST-Segment Elevation Myocardial Infarction Patients. Int Heart J 2017; 58: 486-94. [Crossref]

9. Reinstadler SJ, Stiermaier T, Eitel C, Fuernau G, Saad M, Pöss J, et al. Impact of Atrial Fibrillation During ST-Segment-Elevation Myocardial Infarction on Infarct Characteristics and Prognosis. Circ Cardiovasc Imaging 2018; 11: e006955. [Crossref]

10. Garg L, Agrawal S, Agarwal M, Shah M, Garg A, Patel B, et al. Influence of Atrial Fibrillation on Outcomes in Patients Who Underwent Primary Percutaneous Coronary Intervention for ST-Segment Elevation Myocardial Infarction. Am J Cardiol 2018; 121: 684-9. [Crossref] 
11. Topaz G, Flint N, Steinvil A, Finkelstein A, Banai S, Keren G, et al. Long term prognosis of atrial fibrillation in ST-elevation myocardial infarction patients undergoing percutaneous coronary intervention. Int J Cardiol 2017; 240: 228-33. [Crossref]

12. Çınar T, Keskin M, Işılak Z, Orhan AL. A new predictor for newonset atrial fibrillation in patients with ST elevation myocardial infarction: chronic renal disease. Acta Cardiol 2020; 75: 277-8. [Crossref]

13. Soliman EZ, Prineas RJ, Go AS, Xie D, Lash JP, Rahman M, et al.; Chronic Renal Insufficiency Cohort (CRIC) Study Group. Chronic kidney disease and prevalent atrial fibrillation: the Chronic Renal Insufficiency Cohort (CRIC). Am Heart J 2010; 159: 1102-7. [Crossref]

14. Fauchier L, Bisson A, Clementy N, Vourc'h P, Angoulvant D, Babuty $D$, et al. Changes in glomerular filtration rate and outcomes in patients with atrial fibrillation. Am Heart J 2018; 198: 39-45. [Crossref]

15. Reinecke H, Nabauer M, Gerth A, Limbourg T, Treszl A, Engelbertz C, et al.; AFNET Study Group. Morbidity and treatment in patients with atrial fibrillation and chronic kidney disease. Kidney Int 2015; 87: 200-9. [Crossref]

16. Massicotte-Azarniouch D, Kuwornu JP, Carrero JJ, Lam NN, Molnar AO, Zimmerman D, et al. Incident Atrial Fibrillation and the Risk of Congestive Heart Failure, Myocardial Infarction, End-Stage Kidney Disease, and Mortality Among Patients With a Decreased Estimated GFR. Am J Kidney Dis 2018; 71: 191-9. [Crossref]

17. Kulkarni N, Gukathasan N, Sartori S, Baber U. Chronic Kidney Disease and Atrial Fibrillation: A Contemporary Overview. J Atr Fibrillation 2012; 5: 448.
18. Mrdovic I, Savic L, Lasica R, Krljanac G, Asanin M, Brdar N, et al. Efficacy and safety of tirofiban-supported primary percutaneous coronary intervention in patients pretreated with $600 \mathrm{mg}$ clopidogrel: results of propensity analysis using the Clinical Center of Serbia STEMI Register. Eur Heart J Acute Cardiovasc Care 2014; 3 : 56-66. [Crossref]

19. Levey AS, Eckardt KU, Dorman NM, Christiansen SL, Cheung M, Jadoul $M$, et al. Nomenclature for kidney function and diseaseexecutive summary and glossary from a Kidney Disease: Improving Global Outcomes (KDIGO) consensus conference. Eur Heart J 2020; 41: 4592-8. [Crossref]

20. Saczynski JS, McManus D, Zhou Z, Spencer F, Yarzebski J, Lessard $D$, et al. Trends in atrial fibrillation complicating acute myocardial infarction. Am J Cardiol 2009; 104: 169-74. [Crossref]

21. Rathore SS, Berger AK, Weinfurt KP, Schulman KA, Oetgen WJ, Gersh BJ, et al. Acute myocardial infarction complicated by atrial fibrillation in the elderly: prevalence and outcomes. Circulation 2000; 101: 969-74. [Crossref]

22. McAlister FA, Ezekowitz J, Tarantini L, Squire I, Komajda M, BayesGenis A, et al.; Meta-analysis Global Group in Chronic Heart Failure (MAGGIC) Investigators. Renal dysfunction in patients with heart failure with preserved versus reduced ejection fraction: impact of the new Chronic Kidney Disease-Epidemiology Collaboration Group formula. Circ Heart Fail 2012; 5: 309-14. [Crossref]

23. Ekmekci A, Uluganyan M, Gungor B, Tufan F, Cekirdekci El, Ozcan KS, et al. Comparison of Cockcroft-Gault and modification of diet in renal disease formulas as predictors of cardiovascular outcomes in patients with myocardial infarction treated with primary percutaneous coronary intervention. Angiology 2014; 65: 838-43. [Crossref] 